\title{
First synthesis of 6,7-diaminoindole and 1,2,5-selenadiazolo[3,4-g]indole
}

\author{
Michaela Edin and Spiros Grivas* \\ Unit for Organic Chemistry, Department of Biosciences, Karolinska Institute and Södertörn \\ University College, Novum Research Park, SE-141 57 Huddinge, Sweden \\ E-mail: spiros.grivas@cnt.ki.se
}

(received 20 Sep 99; accepted 13 Feb 00; published on the web 21 Feb 00)

\begin{abstract}
5-Methyl-4-nitro-2,1,3-benzoselenadiazole (1) was converted into 1,2,5-selenadiazolo[3,4g]indole (3) by the Batcho-Leimgruber indole synthesis. Subsequent deselenation afforded 6,7diaminoindole (4) which on treatment with biacetyl afforded 2,3-dimethylpyrrolo[2,3f]quinoxaline (5) in $80 \%$ yield from 3 .
\end{abstract}

Keywords: Benzoselenadiazole, diaminoindole, deselenation, quinoxaline

\section{Introduction}

Aromatic amines represent an important class of compounds for a wide variety of pharmaceuticals, pesticides, additives and dyes. In recent years, mutagenic aminoimidazoquinoxalines, -quinolines and -naphthyridines have been prepared ${ }^{1}$ for analytical purposes and for structure-biological activity studies related to food carcinogens. ${ }^{2}$ Retrosynthetic analysis of some needed bioisosteric pyrroloquinoxalines led to 6,7-diaminoindole (4). Surprisingly, although derivatives of $\mathbf{4}$ are known, ${ }^{3}$ the unsubstituted indole $\mathbf{4}$ has not been reported. Moreover, neither has the possible precursor 6,7-dinitroindole nor any suitable aminonitro(so)indole. On the other hand, deselenation of 2,1,3-benzoselenadiazoles (bsd) has previously afforded ortho-benzenediamines which have then been conveniently converted into, eg, less accessible 4-nitrobenzimidazoles ${ }^{4}$ and elusive 5-nitroquinoxalines. ${ }^{5}$ Thus, we thought that the unsubstituted indole 4 might be obtained from the readily available $\mathbf{1}^{6}$ via the novel 1,2,5-selenadiazolo[3,4-g]indole (3).

This paper communicates the first preparation of selenadiazoloindole $\mathbf{3}$ and diaminoindole $\mathbf{4}$, together with an illustration of their synthetic use en route to nitrogen heterocycles. 

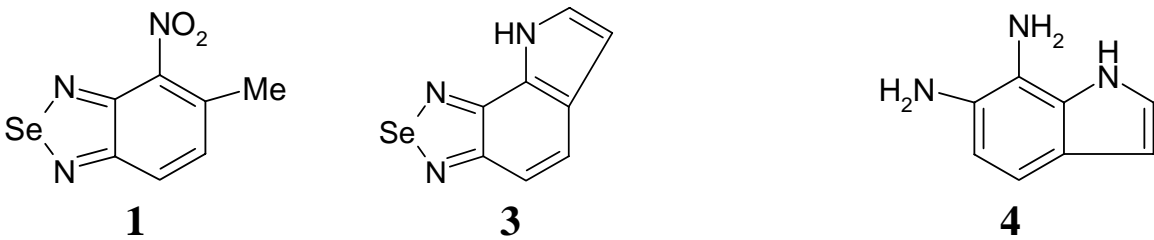

Batcho-Leimgruber indole synthesis ${ }^{7}$ on bsd 1, using $N, N$-dimethylformamide dimethyl acetal (DMFDMA) in acetonitrile or DMF gave the trans isomer $(J=13.1 \mathrm{~Hz})$ of enamine 2 in $84 \%$ isolated yield. The reductive cyclization is usually done with hydrogen over a palladium catalyst or with Raney nickel and hydrazine. ${ }^{7}$ Attempts to transform $\mathbf{2}$ into $\mathbf{3}$ by hydrogenation over $10 \% \mathrm{Pd}-\mathrm{C}$ in THF, at ambient conditions and up to $50 \mathrm{psi}$, gave only intact 2 . Further, no traces of 3 were detected in the dark reaction mixtures produced when hydrogen and Raney nickel in THF and/or alcohols were employed at various temperatures. Heating 2 with hydrazine hydrate and Raney nickel in THF and/or alcohols gave the desired 3 in less than 10\% yield. However, more efficient ring closure to 3 was eventually achieved by heating 2 with iron powder in acetic acid and ethanol, conditions known to convert 4-nitro-bsd into the amino compound without substantial deselenation. ${ }^{8}$

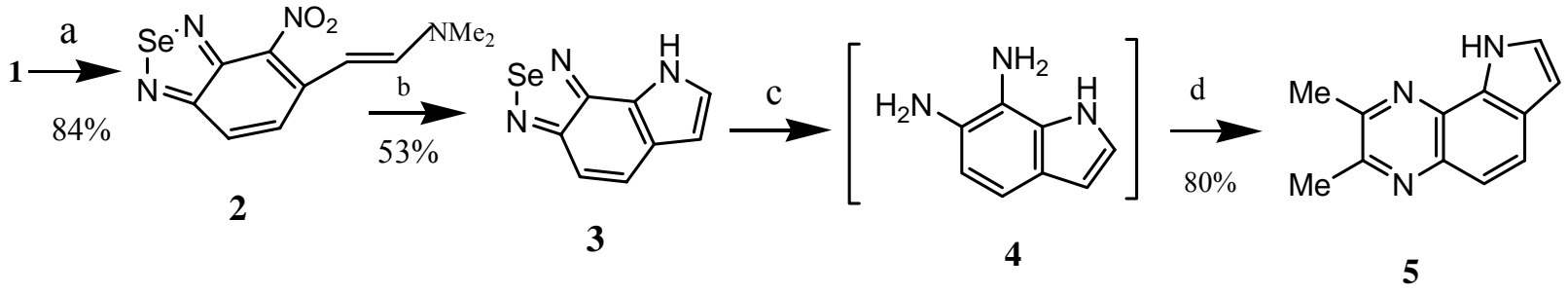

Reagents and conditions: (a) DMFDMA, DMF, $60{ }^{\circ} \mathrm{C}, 3 \mathrm{~h}$ or MeCN, reflux, $2 \mathrm{~h}$; (b) Fe, AcOH:EtOH 1:1, reflux, 30 min; (c) $80 \% \mathrm{~N}_{2} \mathrm{H}_{4}$, Raney nickel, $\mathrm{MeOH}$, reflux, 4 h; (d) $\mathrm{Ac}_{2}$, $\mathrm{MeOH}, 56{ }^{\circ} \mathrm{C}, 2.5 \mathrm{~h}$.

Deselenation of bsd is usually accomplished by, eg, hydrogen iodide in hydrochloric acid, ${ }^{4,5}$ stannous chloride and hydrochloric acid, ${ }^{9}$ zinc and hydrochloric acid ${ }^{10}$ or by ammonium sulfide. ${ }^{1 \mathrm{a}, 4,5 \mathrm{a}}$ Because of the potential oligomerization of the 2 -unsubstituted indole $\mathbf{3}$ in acid, ${ }^{11}$ we first attempted deselenation by ammonium sulfide in ethanol. In contrast to previous efficient deselenations with this reagent, ${ }^{1 \mathrm{a}, 4,5 \mathrm{a}}$ only a small amount of $\mathbf{3}$ was deselenated even in higher boiling alcohols. However, the desired diaminoindole $4^{12}$ could be obtained in high yield by heating 3 with hydrazine hydrate and Raney nickel. Treating crude 4 with selenium dioxide gave selenadiazoloindole 3, quantitatively and spontaneously as indicated by TLC. Furthermore, crude 4 was treated with diacetyl to provide the apparently unknown pyrroloquinoxaline 5 in $80 \%$ isolated yield from 3. Other pyrrolo[2,3-f]quinoxalines have been prepared and tested for biological activity. ${ }^{13}$ Derivatives of the sulfur analogue of $\mathbf{3}$ have been obtained via Fisher indole synthesis on 4-amino-benzothiadiazole. ${ }^{3,14}$

In conclusion, the Batcho-Leimgruber indole synthesis has been successfully applied to $\mathbf{1}$ for the 
synthesis of unsubstituted 6,7-diaminoindole. Since the indole unit occurs widely in nature, and its chemistry is one of the most active areas of heterocyclic chemistry, we believe that access to ortho-diaminoindoles will find many applications. ortho-Diamines are easily transformed into, $e g$, benzimidazoles, quinoxalines and benzodiazepines which are often found in numerous pharmaceuticals. Work is in progress on the preparation of the isomeric 5,6- and 4,5diaminoindoles.

\section{Experimental Section}

General Procedures. Yields are not optimized. Evaporations were performed under reduced pressure at $40{ }^{\circ} \mathrm{C}$. All reactions and purifications were monitored by thin layer chromatography (UV detection and Van Urk's reagent ${ }^{15}$ ) on aluminium sheets coated with silica gel $60 \mathrm{~F}_{254}$ plates (Merck). 'Flash' and 'dry flash' column chromatography was performed on silica gel 60 (35-70 $\mu$, Grace). Melting points (uncorrected) were determined on a Büchi Melting Point B-545. The ${ }^{1} \mathrm{H}$ and ${ }^{13} \mathrm{C}$ NMR spectra were recorded on a Bruker DPX 300 spectrometer at $25{ }^{\circ} \mathrm{C}$, and referenced to the solvent $\left(\mathrm{Me}_{2} \mathrm{SO} \delta_{\mathrm{H}} 2.50\right.$ and $\delta_{\mathrm{C}} 39.5$ or $\mathrm{CHCl}_{3} \delta_{\mathrm{H}} 7.26$ and $\left.\delta_{\mathrm{C}} 77.0\right)$. Gradient HMBC experiments were used for the assignments. Coupling constants $J$ are given in $\mathrm{Hz}$ and without sign. The infrared spectra were recorded on a Perkin-Elmer FT-IR 1600 instrument. The electrospray mass spectra were taken on a Perkin-Elmer API 150Ex spectrometer and the EI (70 $\mathrm{eV}$, direct insertion) mass spectrum of $\mathbf{1}$ was taken on a Micromass Platform spectrometer. Ions containing isotopes other than ${ }^{80} \mathrm{Se}$ are not listed.

Materials. Unless otherwise stated, these were commercial samples. All organic solvents were either freshly distilled or of $p a$ quality. Solvent mixtures are defined by volume ratios (v/v). Petrol refers to petroleum ether, bp $60-70{ }^{\circ} \mathrm{C}$.

5-Methyl-4-nitro-2,1,3-benzoselenadiazole (1). Prepared as in the lit. ${ }^{6 \mathrm{a}} \mathrm{Mp}: 196-8{ }^{\circ} \mathrm{C}\left[\right.$ lit. $^{6 \mathrm{a}}$ $192-4{ }^{\circ} \mathrm{C}$; lit. $\left.{ }^{6 \mathrm{~b}} 194-5{ }^{\circ} \mathrm{C}\right] .{ }^{1} \mathrm{H}$ NMR $\left(\mathrm{DMSO}-d_{6}\right) \delta 7.98(1 \mathrm{H}, \mathrm{d}, J=9.2,7-\mathrm{H}), 7.60(1 \mathrm{H}, \mathrm{d}, J=9.2$, 6-H), 2.44 (3H, s, Me); ${ }^{13} \mathrm{C}$ NMR (DMSO-d $) \delta 158.25$ (7a-C), 150.63 (3a-C), 141.69 (4-C), 131.92 (7-C), 131.61 (5-C), 125.46 (6-C), 16.99 (Me); IR (KBr, cf lit. ${ }^{6 c}$ ) 3084, 1617, 1527, 1504, 1493, 1381, 1359, 1343, 1323, 1276, 823, $733 \mathrm{~cm}^{-1}$; MS m/z: 243 (M+, 32), 226 (42, M-OH, ortho-effect), 213 (5, M-NO), 197 (5, M-NO2), 117 (100).

(E)-5-[2-(Dimethylamino)ethenyl]-4-nitro-2,1,3-benzoselenadiazole (2). Oven-dried and septum-capped flasks were used. DMFDMA $(2.8 \mathrm{~mL}, 21 \mathrm{mmol})$ was added dropwise from a syringe, at rt, to a stirred slurry of benzoselenadiazole $\mathbf{1}(2.2 \mathrm{~g}, 9 \mathrm{mmol})$ in acetonitrile $(30 \mathrm{~mL})$ under a nitrogen atmosphere. The mixture darkened during the addition. Heating at reflux for $2 \mathrm{~h}$ (TLC: petrol/EtOAc 1:1) gave a dark red solution which was concentrated to give $2.2 \mathrm{~g}$ of 2 (84\%). This was converted into 3 without further purification. An analytical sample was obtained by crystallization from isopropanol: $\mathrm{mp} 186-7^{\circ} \mathrm{C} ;{ }^{1} \mathrm{H}$ NMR $\left(\mathrm{DMSO}-d_{6}\right) \delta 7.99(1 \mathrm{H}, \mathrm{d}, J=9.8,7$ - 
H), $7.92\left(1 \mathrm{H}, \mathrm{d}, J=13.1,2^{\prime}-\mathrm{H}\right), 7.68(1 \mathrm{H}, \mathrm{dd}, J=9.85,0.5,6-\mathrm{H}), 5.41\left(1 \mathrm{H}, \mathrm{d}, J=13.1,1^{\prime}-\mathrm{H}\right)$, $3.01(6 \mathrm{H}, \mathrm{s}, \mathrm{N}-\mathrm{Me}) ;{ }^{13} \mathrm{C}$ NMR (DMSO- $\left.d_{6}\right) \delta 157.08$ (7a-C), 152.82 (3a-C), 149.93 (2'-C), 135.39 (5-C), 132.84 (4-C), 127.11 (6-C), 124.77 (7-C), 88.09 (1'-C), 41.35 ( $N$-Me); IR (KBr) 2919, 2802, 1620, 1599, 1484, 1394, 1238, 1115, 976, 814, $750 \mathrm{~cm}^{-1}$; MS m/z: $299\left(\mathrm{MH}^{+}\right)$.

1,2,5-Selenadiazolo[3,4-g]indole (3). A mechanically stirred mixture of $2(1.5 \mathrm{~g}, 5.0 \mathrm{mmol})$ and iron powder $(3.0 \mathrm{~g}, 53.7 \mathrm{mmol})$ in absolute ethanol/glacial acetic acid 1:1 $(60 \mathrm{~mL})$ was cautiously heated to reflux under a nitrogen atmosphere. After $30 \mathrm{~min}$ (TLC: petrol/EtOAc 1:1) the mixture was allowed to reach rt, poured into water $(130 \mathrm{~mL})$ and filtered through Celite. The pad was washed with $\mathrm{Et}_{2} \mathrm{O}(150 \mathrm{~mL})$. After separating the ether, the aqueous layer was further extracted with $\mathrm{Et}_{2} \mathrm{O}(2 \mathrm{x})$. The organic layer was washed with water and saturated $\mathrm{Na}_{2} \mathrm{CO}_{3}$ solution until the aqueous layer reached $\mathrm{pH} 8$. The ether layer was washed with brine, filtered and concentrated onto silica. 'Dry flash' chromatography (petrol/EtOAc 1:1) and collection of the yellow band gave $590 \mathrm{mg}(53 \%)$ of 3 . An analytical sample was obtained by sublimation under vacuum: mp 190-2 ${ }^{\circ} \mathrm{C} ;{ }^{1} \mathrm{H}$ NMR $\left(\mathrm{CDCl}_{3}\right) \delta 9.6(1 \mathrm{H}, \mathrm{br} \mathrm{s}, 8-\mathrm{H}), 7.70(1 \mathrm{H}, \mathrm{dd}, J=9.3,0.4,5-\mathrm{H})$, $7.42(1 \mathrm{H}, \mathrm{d}, J=9.3,4-\mathrm{H}), 7.27(1 \mathrm{H}, \mathrm{dd}, J=3.1,2.3,7-\mathrm{H}), 6.61(1 \mathrm{H}, \mathrm{dd}, J=2.8,2.3,6-\mathrm{H}) ;{ }^{1} \mathrm{H}$ NMR (DMSO-d $\left.)_{6}\right) \delta 12.5(1 \mathrm{H}$, br s, $8-\mathrm{H}), 7.73(1 \mathrm{H}, \mathrm{d}, J=9.2,5-\mathrm{H}), 7.36(1 \mathrm{H}$, app t, $J=2.7,7-$ H), $7.31(1 \mathrm{H}, \mathrm{d}, J=9.2,4-\mathrm{H}), 6.57(1 \mathrm{H}, \mathrm{dd}, J=2.6,2.0,6-\mathrm{H}) ;{ }^{13} \mathrm{C}$ NMR (DMSO-d 6 ) $\delta 159.53$ (3a-C), 150.72 (8b-C), 126.80 (5-C), 125.72 (5a-C), 124.63 (8a-C), 124.57 (7-C), 115.09 (4-C), 104.57 (6-C); IR (KBr) 3157, 3089, 2996, 2900, 1606, 1539, 1496, 1410, 1365, 1329, 1276, 1248, 1028, 775, $653 \mathrm{~cm}^{-1}$; MS m/z: $224\left(\mathrm{MH}^{+}\right)$.

2,3-Dimethylpyrrolo[2,3-flquinoxaline (5). To a stirred solution of 3 (160 mg, $0.7 \mathrm{mmol})$ and $80 \%$ hydrazine hydrate $(82 \mu \mathrm{L}, 2.1 \mathrm{mmol})$ in $\mathrm{MeOH}(40 \mathrm{~mL})$, at $\mathrm{rt}$, was added a spatulatip of Raney nickel (W-2) under a nitrogen atmosphere. Evolution of gas took place. The reaction mixture was heated to reflux and an additional $82 \mu \mathrm{L}$ of $80 \%$ hydrazine hydrate was added after $3 \mathrm{~h}$ at reflux. After $45 \mathrm{~min}$ (TLC: EtOAc) the mixture was allowed to cool to rt, filtered through Celite, and the pad was washed with $\mathrm{MeOH}(40 \mathrm{~mL})$. The light yellow filtrate containing $4^{12}$ (which turned red upon exposure to air) was placed under a nitrogen atmosphere, and diacetyl $(123 \mu \mathrm{L}, 1.4 \mathrm{mmol})$ was added. The solution was stirred at $56{ }^{\circ} \mathrm{C}$ for $2 \mathrm{~h}$. TLC (EtOAc) indicated some unreacted 4 . An additional portion of diacetyl $(61 \mu \mathrm{L})$ was added and after another $30 \mathrm{~min}$ TLC indicated complete consumption of 4 . The reaction mixture was diluted with water $(10 \mathrm{~mL})$ and evaporated to about half of the original volume, whereupon crystals formed. The mixture was cooled, the precipitate was collected and dried in a vacuum desiccator to give $65 \mathrm{mg}$ of 5 . The mother liquor was diluted with $\mathrm{CH}_{2} \mathrm{Cl}_{2}$ and brine. The aqueous layer was extracted with $\mathrm{CH}_{2} \mathrm{Cl}_{2}$ and the combined organic phases were washed with water and brine. Drying $\left(\mathrm{Na}_{2} \mathrm{SO}_{4}\right)$ and evaporation of the solvent afforded another $48 \mathrm{mg}$ of 5. Yield: $80 \%$. An analytical sample was obtained by sublimation under vacuum: $\mathrm{mp} 243-4{ }^{\circ} \mathrm{C} ;{ }^{1} \mathrm{H}$ NMR $\left(\mathrm{CDCl}_{3}\right) \delta 9.8(1 \mathrm{H}$, br s, $9-$ H), $7.89(1 \mathrm{H}, \mathrm{d}, J=8.8,6-\mathrm{H}), 7.63(1 \mathrm{H}, \mathrm{d}, J=8.8,5-\mathrm{H}), 7.37(1 \mathrm{H}, \mathrm{dd}, J=3.0,2.5,8-\mathrm{H}), 6.72$ $(1 \mathrm{H}, \mathrm{dd}, J=3.0,2.2,7-\mathrm{H}), 2.74(6 \mathrm{H}, \mathrm{s}, 2-$ and $3-\mathrm{Me}) ;{ }^{13} \mathrm{C} \mathrm{NMR}\left(\mathrm{CDCl}_{3}\right) \delta 150.61$ (3- or 2-C), 150.23 (2- or 3-C), 138.66 (4a-C), 130.81 (9b-C), 129.67 (9a-C), 126.09 (6a-C), 123.91 (8-C), 123.65 (6-C), 120.06 (5-C), 104.11 (7-C), 22.89 (3- or 2-Me), 22.77 (2- or 3-Me); IR (KBr) 
3175, 1498, 1379, 1360, 1348, 1167, $796 \mathrm{~cm}^{-1}$; MS m/z: $198\left(\mathrm{MH}^{+}\right)$.

\section{Acknowledgments}

We thank the Swedish Council for Forestry and Agricultural Research (SJFR), the National Institutes of Health (USA) and the Lawrence Livermore National Laboratory for financial support.

\section{References}

1. (a) Grivas, S.; Tian, W.; Ronne, E.; Lindström, S.; Olsson, K. Acta Chem. Scand. 1993, 47, 521. (b) Grivas, S.; Schuisky, P. Heterocycles 1998, 48, 1575.

2. Knize, M. G.; Salmon, C. P.; Pais, P.; Felton, J. S. Adv. Exp. Med. Biol. 1999, 459, 179.

3. (a) Patent in Russian, Chem. Abstr.105:190924 (b) Chetverikov, V. P.; Titov, G. A.; Bundel', Yu. G.; Luk'yanova, M. S.; Kurilenko, V. M. Pharm. Chem. J. (Engl. Transl.) 1987, 21, 874.

4. Tian, W.; Grivas, S. Synthesis 1992, 1283.

5. (a) Grivas, S.; Tian, W.; Andersson, R. J. Chem. Res. (S) 1992, 328; (M) 2701. (b) Grivas, S.; Tian, W. Acta Chem. Scand. 1992, 46, 1109. (c) Tian, W.; Grivas, S. J. Heterocycl. Chem. 1992, 29, 1305. (d) Tian, W.; Grivas, S.; Olsson, K. J. Chem. Soc., Perkin Trans. 1 1993, 257.

6. (a) Sawicki, E.; Carr, A. J. Org. Chem. 1958, 23, 610. (b) Pesin, V. G.; Muravnik, R. S. Latvijas PSR Zinatnu Akad. Vestis, Kim. Ser. 1964, 725 (CA63:4279). (c) Bird, C. W.; Cheeseman, G. W. H. Tetrahedron 1964, 20, 1701.

7. (a) Clark, R. D.; Repke, D. B. Heterocycles 1984, 22, 195. (b) Sundberg, R. J. In Best Synthetic Methods, Indoles; Academic Press, 1996; pp 7-11.

8. Efros, L. S.; Todres-Selektor, Z. V. J. Gen. Chem. USSR (Engl. Transl.) 1957, 27, 1064.

9. Tsubata, Y.; Suzuki, T.; Miyashi, T. J. Org. Chem. 1992, 57, 6749.

10. Sawicki, E.; Carr, A. J. Org. Chem. 1957, 22, 503.

11. Katritzky, A. R.; Rees, C. W., Eds. Comprehensive Heterocyclic Chemistry; Pergamon Press: Oxford, 1984; Vol. 4, pp 206-208.

12. ${ }^{1} \mathrm{H}$ NMR $\left(\mathrm{CDCl}_{3}\right) \delta 8.0(1 \mathrm{H}$, br s, $1-\mathrm{H}), 7.06(1 \mathrm{H}, \mathrm{d}, J=8.2,4-\mathrm{H}), 6.94(1 \mathrm{H}$, br d, $J=1.9$, 2-H), $6.64(1 \mathrm{H}, \mathrm{d}, J=8.2,5-\mathrm{H}), 6.42(1 \mathrm{H}$, app br t, $J=1.9,3-\mathrm{H}), 3.2(4 \mathrm{H}$, br s, 6- and 7$\mathrm{NH}_{2}$ ).

13. (a) Patent in Russian, Chem. Abstr. 104:148908; (b) patents in Japanese, Chem. Abstr. 125:33684 and 125:114703.

14. (a) Titov, G. A.; Chetverikov, V. P.; Bundel', Yu. G.; Malyuga, O. A.; Ivchenko, T. I.; Alekseeva, E. N. Pharm. Chem. J. (Engl. Transl.) 1987, 21, 867. (b) Patent in Russian, CA105:226566.

15. Stahl, E.; Kaldewey, H. Hoppe-Seylers Z. Physiol. Chem. 1961, 323, 182. 